\title{
Characterization of European Medieval Silver Bars Using Micro X-ray Fluorescence, Conductivity Meter and Scanning Electron Microscopy
}

\author{
Ahmad Nizamedien Barzingi \\ Department of Chemistry, College of Education, University of Garmian, University in Kalar, Iraq
}

\section{A B S T R A C T}

The objective of this paper is to use $\mu$-X-ray fluorescence (XRF) analysis to evaluate the fineness and components of European Medieval Silver Bars samples. Conductivity measurements were used to assess the fineness and localization of the faults found in the samples. Because unevenness causes a change in conductivity, the tests were performed on the flattest areas of the Bars. Some rods, such as B3 and B9, have greater conductivity than others. All bars were subjected to the segregation test. In the instance of certain bars, it was not always practicable to categorically state that segregation had happened. There is no diminishing conductivity curve as one moves away from the zero height, as there is for bars B1, B8, and B9. As a result, there may be no solidification on these bars from Obverse to Reverse. A scanning electron microscope was used to record the following bars at various positions on the bars, and quantitative determinations were achieved using energy-dispersed XRF analysis through intensity measurements of the element-specific wavelength.

Index Terms: Silver bars, X-ray fluorescence, Micro-X-ray fluorescence, Conductivity Meter, Scanning electron microscope

\section{INTRODUCTION}

Money has been used in Europe for over 2600 years to denote coined metal, particularly in the form of coins. When the term money (derived from the Middle High German "Geld") is reduced to its most fundamental meanings (replacement, compensation, value, price, retribution), all that remains is a widely accepted standard of billing, value storage, and pricing that has developed from barter. This standard is usually based on a certain amount of a coveted and durable material, often a metal, the most important raw material of antiquity. The

\begin{tabular}{|l|l|}
\hline Access this article online \\
\hline DOI: 10.21928/uhdjst.v5n2y2021.pp57-65 & $\begin{array}{l}\text { E-ISSN: 2521-4217 } \\
\text { P-ISSN: 2521-4209 }\end{array}$ \\
\hline
\end{tabular}

Copyright (C) 2021 Barzingi. This is an open access article distributed under the Creative Commons Attribution Non-Commercial No Derivatives License 4.0 (CC BY-NC-ND 4.0) importance of metals is demonstrated by the fact that entire periods of history are called after them: the Copper Age (end of the Neolithic to before the $3^{\text {rd }}$ century BC), the Bronze Age (before 2200 BC in Europe), and the Iron Age (before 1200 BC in Europe) (in Central Europe before 1200 BC to after 500 AD) [1]. Hence, it is not unexpected that a metal bar has been used for almost 4000 years, since the Bronze Age, as one of the original and natural forms of money (in addition to non-metallic types of money) (Fig. 1) [2].

The oldest bronze casting sites in Central Europe and Germany that have been verified to make bar bars in stone molds are in Saxony-Rotta Anhalt's and Schackstedt (evidence is available in the State Museum of Saxony-Anhalt in Halle). Since the early Bronze Age, metal bars of varying forms and weights have been used in this manner to preserve payment and value (at least verifiable from approx. 2700 BC) [4] and are also used today in many international transactions (e.g. the

Corresponding author's e-mail: Ahmad Nizamedien Barzingi, Department of Chemistry, College of Education, University of Garmian, University in Kalar, Iraq. E-mail: Ahmad.barzingi@garmian.edu.krd

Received: 23-09-2021 Accepted: 20-11-2021 Published: 25-11-2021 
method of choice for repaying national debts by switching gold bars in the Federal Reserve Bank of New York [5].

Bullion's journey can be traced throughout human history and to every corner of the globe. The ancient Egyptians utilized bar money, which was made out of precious metal rings and pieces imprinted with the Pharaoh's name. Special officials were assigned to oversee the quality and weight of silver bars in Mesopotamia during the period of Babylonian King Hammurabi (1792-1750 BC) [6]. Since silver has been in Mesopotamia since $2100 \mathrm{BC}$ was the measure of value for goods, wages and prices are already in the $18^{\text {th }}$ century $\mathrm{BC}$ a standard house for silver as a means of payment in Babylon, probably the earliest documented forerunner of DIN, known [7].

For commercial reasons, the Celts and Teutons in Northern Europe utilized standardized bronze rings and high-quality iron bars [4].

The Romans, together with the Greeks, are regarded as the forefathers of European civilization, and they utilized metal ingots as currency until approximately $200 \mathrm{BC}$ [8]. The actual currency was not used until the $7^{\text {th }}$ century $B C$, when it was developed (Fig. 2), most likely by Lydian king Alyattes II, the father of the legendary Croesus [9].

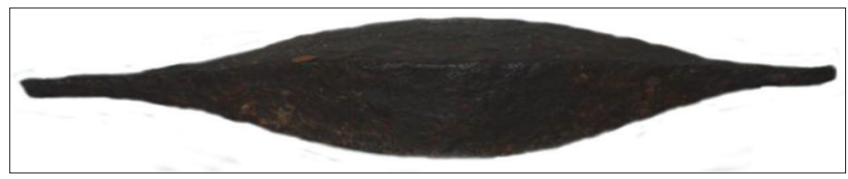

Fig. 1. Celtic pointed bars made of iron, approx. $5 \mathrm{~kg}$, around 100 BC. Chr. To 100 AD. Such high-quality iron bars from the Celtic and Germanic tribes were a sought-after commodity and were mainly exported to Rome. Among other things, high-quality Roman swords were forged from it [3].

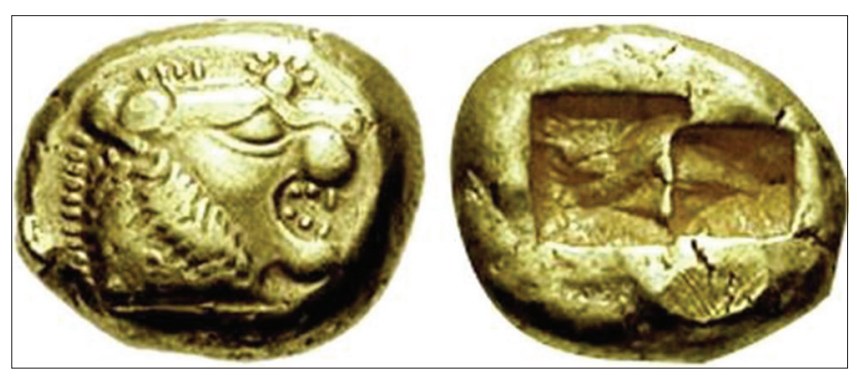

Fig. 2. Electron trite (third stater) of the Lydian king Alyattes II (approx. 613-556 BC), $4.71 \mathrm{~g}, 12 \mathrm{~mm}$, enlarged illustration [3]. Alyattes was the father of Croesus and is considered the inventor of minted money [9].
Small electron bars (from Latin "electrum" = amber, signifying a natural mixture of gold and silver) were used to create the currency[10]. A seal (lion's head as the Mermnaden dynasty's coat of arms) was imprinted on the first coin's hour of birth to indicate its origin and ensure its value]. Coincidentally, about the same period, the first counterfeit coins appeared. These are lead bars that have had an electron coat applied to them (Herodotus $5^{\text {th }}$ century BC). To confirm the coins' validity, they had to be sliced apart or given a deep notch, a procedure that left traces on several ancient coins that may still be seen today.

Gold and silver bars were used to replace money in Rome until the fall of the Western Roman Empire (AD 474), despite the highly established Roman currency system (Figs 4-6).

From approximately $300 \mathrm{AD}$, the Roman emperor gave legionaries a 5-year present (donative) consisting of five gold coins (aurei or solidi, Fig. 3) and a silver bar weighing one Roman pound (327, $63 \mathrm{~g})$ [11].

A silver bar of this size was valued at around $200 \mathrm{~L}$ of wine, two annual rations of food, or about a third of the typical

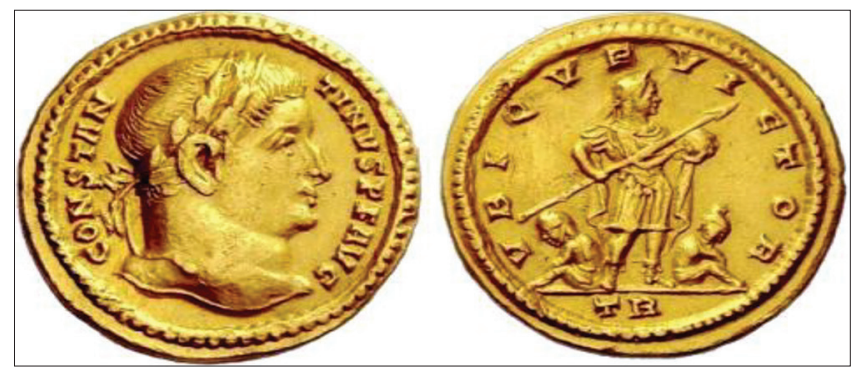

Fig. 3. Solidus of the Roman Emperor Constantinus (306-337 AD), $4.56 \mathrm{~g}, 20 \mathrm{~mm}$, minted around 310-313 in Trier, Fig. Enlarged (Lehmann 2010b) [3]. Flavius Valerius Constantinus, also known as Constantine the Great, introduced the solidus in 309 AD, which replaced the aureus that ran before it as a Roman imperial gold coin [10].

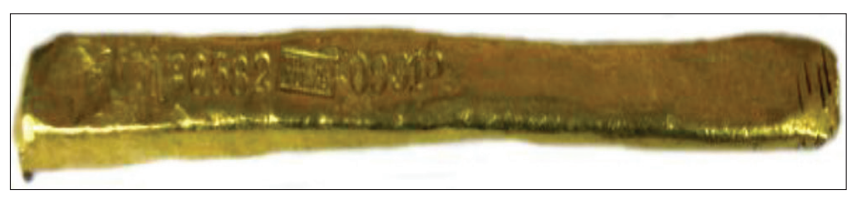

Fig. 4. Roman gold bar from the Munich State Coin Collection. This bar probably only represents a form of transport of the gold to the mint. The gold bar was once owned by the Swiss Federal Bank, which determines the fineness and - regardless of the art-historical value of the bar - had this stamped on the bar next to an inventory number. The fineness is $99.15 \%$. The bar shape has been a popular shape for non-ferrous and precious metals since the Bronze Age because it made it easier to cut the bar (Photo: Lehmann). 


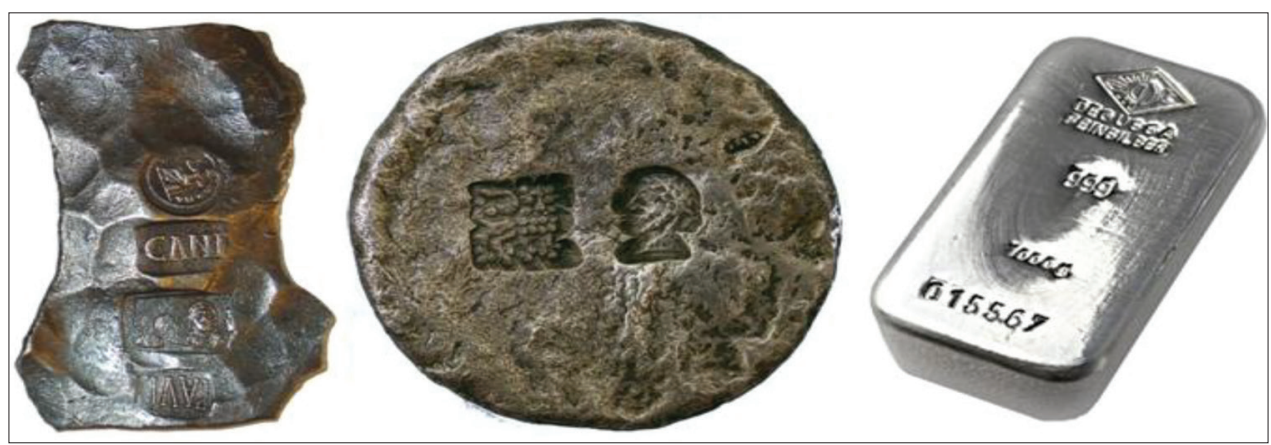

Fig. 5. Overview of silver bars from different epochs. On the left is a Roman silver bar (target weight: $327.63 \mathrm{~g}$ ), $7 \times 10 \mathrm{~cm}$ ), in the middle a medieval German bar (one silver mark nominally $233.856 \mathrm{~g}, 6-7 \mathrm{~cm}$ ), on the right modern silver bar $(1 \mathrm{~kg})$. While you could still buy a slave for around 3 Roman bars and a small piece of land for the medieval bar, at the end of $2010300 \mathrm{~g}$ of fine silver cost just under 200 euros [12].

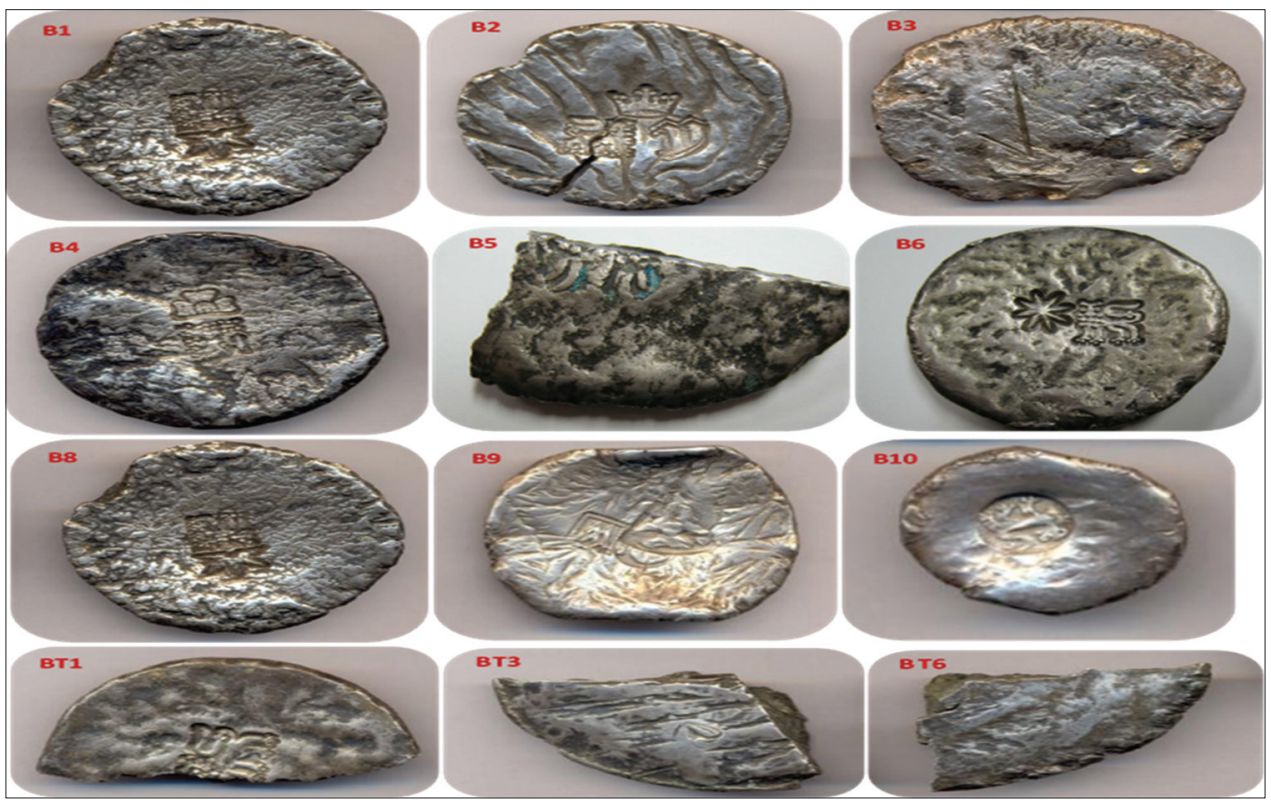

Fig. 6. Silver bars samples.

slave price [13]. Antiquity and the Middle Ages silver bars had a radically different form and shape from today's bar silver, as seen in (Fig. 5). The double ax or skin form is seen on the Roman silver bars illustrated here [8], although most items from the German Middle Ages were shaped like a hemisphere or dome [14].

In general, $\mathrm{X}$-ray fluorescence $(\mathrm{XRF})$ is a non-destructive technique for the qualitative and quantitative evaluation of inorganic solids, liquids, and burned organic compounds that are based on the interaction of X-rays with matter. Cement, glass, and ceramic industries consume rocks and slag. It has become an established routine method for archaeometric investigations on precious metal objects (coins, jewelery, etc.) and other historical objects for several years, especially since the development of transportable devices in archaeology, where it is used to quickly classify found objects and has been an established routine method for archaeometric investigations on precious metal objects (coins, jewelery, etc.). This approach is also appropriate for multi-elemental analysis of inorganic components in an organic matrix, for example to identify inorganic impurities in biological samples, only elements with an atomic number $Z>13$ (carbon) may typically be examined [15]. More recent developments also allow the analysis of aerosols and gases.

The $\mathrm{X}$-ray radiation used in $\mathrm{XRF}$ is electromagnetic radiation with a wavelength in the range of $0.01-10 \mathrm{~nm}$ and, together with the $\gamma$-rays, forms the short-wave limit range of the electromagnetic spectrum [16]. 
Electron microscopy enlarges pictures of things using electron beams. It is utilized for micrometer-scale surface analysis. When compared to a light microscope, accelerated electrons may attain a resolution a 1000 times $>3 \mathrm{~nm}$, allowing finer features to be distinguished. The device is composed of four assemblies: an electron gun, electron optics, a sample holder, and an electron detector.

When an electron beam collides with a sample surface, two types of interactions occur elastic interactions, which change the direction of the electrons without altering their energy, and inelastic interactions, which transfer the electron energies partially or entirely to the sample atoms.

Secondary electrons, Auger electrons, X-rays, heat, and light are then emitted by the excited material (electromagnetic radiation over many frequencies). Secondary electrons can be utilized to generate images [17].

The collision of an electron with an atom changes the direction of the electron but the speed and therefore the kinetic energy stays unchanged in elastic scattering. Some electrons lose their energy due to inelastic collisions and remain in the material after numerous collisions.

The majority of the energy is emitted from the surface as backscattered electrons. Secondary electrons, which are particularly crucial for image production in the scanning electron microscope (SEM), are produced in the condition of inelastic scattering. These are produced by the interaction of high-energy electrons in the beam with weakly bound electrons in the solid's conduction band, which results in the release of conduction electrons. Secondary electrons are created across the beam's interaction region with the material, but because of their low energy, they are quickly absorbed again. Only secondary electrons produced near the sample's surface can escape. Small elevations on the sample surface result in a shorter electron route length than level regions, allowing more secondary electrons to escape.
Electrical conductivity is a critical material characteristic that not only tells us how effectively a metal conducts electrical current, but also allows us to make judgments about its composition, microstructure, and mechanical capabilities.

The measurement of conductivity is based on the principle of measuring resistance. An electric current is produced in the material to be studied using a probe for this purpose, and the electrical resistance of the substance is measured. The reciprocal value of the electrical resistance determines conductivity.

$$
\gamma=\frac{1}{\rho}=\frac{G}{s}=\frac{1}{R \cdot s}
$$

$\gamma$ : Electrical conductivity/conductivity $\left(\mathrm{Sm}^{-1}\right)$

$\rho$ : The specific electrical resistance $(\Omega \mathrm{m})$

$G$ : The electrical conductance, measured in Siemens $(S)$ $S: S$ : The length of Specimen measured in meters $(\mathrm{m})$,

$\mathrm{R}$ : The resistance, measured in ohms $(\Omega)$

\section{MATERIALS AND METHODS}

\subsection{Conductivity Meter}

The conductivity measurements were performed using a "Hocking" "AutoSigma 2000" instrument. The probe has an interior diameter of $11.5 \mathrm{~mm}$ and an exterior diameter of $12.5 \mathrm{~mm}$, and it operates at a frequency of $60 \mathrm{~Hz}$.

Conductivity measurements were used to attempt to identify the fineness and position of the flaws on the sample. The stability of the device display was verified before each measurement. A copper standard was measured 3 times before and after point measurements, and a copper standard was measured 3 times beneath plastic film, to evaluate device drift (Table 1).

\subsection{SEM}

XL 30, JEOL JSM-6700F Manufacturer: Philips Electronics was used for the recordings, and this has an acceleration voltage of $0.5-30 \mathrm{kV}$. The device has a secondary

\section{TABLE 1: Stability of the measuring device}

\begin{tabular}{|c|c|c|c|c|}
\hline \multirow[t]{2}{*}{ Bar money } & $\begin{array}{l}\text { Conductivity } \\
\mathrm{S} / \mathrm{m}^{*} 10^{6}\end{array}$ & $\begin{array}{l}\text { Conductivity } \\
S / m^{*} 10^{6}\end{array}$ & $\begin{array}{l}\text { Conductivity } \\
\mathrm{S} / \mathrm{m}^{*} 10^{6}\end{array}$ & $\begin{array}{l}\text { Conductivity } \\
S / m^{*} 10^{6}\end{array}$ \\
\hline & Average 1 & Average 2 & Average - Foil 1 & Average -Foil 2 \\
\hline B8 (Obvers) & 58.6 & 58.567 & 58.3 & 58.4 \\
\hline B2 (Obvers) & 58.7 & 58.71 & 58.367 & 58.367 \\
\hline B2 (Reverse) & 58.667 & 58.7 & 58.33 & 58.366 \\
\hline
\end{tabular}


electron detector, backscattered electron detector, $\mathrm{Si}$ (Li) semiconductor detector as a detector.

\subsection{XRF Spectroscopy}

The measurements with $\mu$-XRF analysis aimed to determine the fineness and the components of the bars B1, B2, B3, B4, B6, B8, B9, B10, BT1, BT3, BT6 (Table 2).

The "Eagle $\mu$-Probe II" device from EDAX was used for the measurement. The device has an X-ray tube with a beryllium window, rhodium target, an acceleration voltage of 10-40 $\mathrm{keV}$, a cathode current of 40-1000 $\mu \mathrm{A}$ and a $\mathrm{Si}$ (Li) detector was used as a detector.

\section{RESULTS AND DISCUSSION}

\subsection{Conductivity Measurement}

The conductivity of the following bars was measured: B1, B2, B3, B4, B5, B6, B8, B9, B10, BT1, BT3, BT6. (Fig. 6). Because

$\begin{aligned} & \text { TABLE 2: Silver bars description in term of weight } \\
& \text { and dimension }\end{aligned}$
\begin{tabular}{lcc}
\hline No. & Weight (g) & Dimension (cm) \\
\hline B1 & 191.4 & $5.9 \times 1.2$ \\
B2 & 187.5 & $6 \times 1.1$ \\
B3 & 246.3150 & $6.3 \times 1.09$ \\
B4 & 249.149 & $6.7 \times 1.2$ \\
B5 & 187.232 & \\
B6 & 197.2456 & $5.8 \times 1.3$ \\
B8 & 211.790 & $6.1 \times 1.1$ \\
B9 & 132.0670 & $6.4 \times 1.2$ \\
B10 & 128.876 & $5.3 \times 1.08$ \\
BT1 & 71.165 & \\
BT3 & 64.317 & \\
BT6 & 62.835 & \\
\hline
\end{tabular}

\section{TABLE 3: Conductivity of the bars with standard} deviation $(\sigma)$

\begin{tabular}{lccccc}
\hline \multicolumn{6}{l}{ Conductivity $\left(\mathbf{S} / \mathbf{m}{ }^{*} \mathbf{1 0} \mathbf{6}^{\mathbf{6}}\right)$} \\
\hline No. & Bars & Obvers & Revers & $\boldsymbol{\sigma}$ (Obvers) & $\boldsymbol{\sigma}$ (Revers) \\
\hline 1 & B1 & 16.05 & 10.41 & 2.45 & 1.98 \\
2 & B2 & 13.16 & 10.07 & 2.85 & 3.15 \\
3 & B3 & 40.51 & 33.95 & 3.25 & 1.9 \\
4 & B4 & 16.14 & 11.73 & 1.47 & 1.67 \\
5 & B5 & 20.03 & 12.69 & 0.75 & 1.84 \\
6 & B6 & 20.34 & 14.63 & 1.27 & 2.45 \\
7 & B8 & 15.46 & 12.5 & 1.06 & 3.39 \\
8 & B9 & 23.87 & 18.98 & 1.13 & 2.87 \\
9 & B10 & 36.96 & 24.76 & 5.19 & 0.40 \\
10 & BT1 & 20.40 & 13.89 & 0.53 & 2.23 \\
11 & BT3 & 20.06 & 11.27 & 0.29 & 2.37 \\
12 & BT6 & 21.65 & 18.06 & 0.19 & 5.41 \\
\hline
\end{tabular}

unevenness affects conductivity, the tests were taken on the flattest areas of the bars. On each sample, 10 points on the front and 10 points on the reverse were chosen. Because of unbalancing, several samples could not be measured to 10 points. The conductivity was measured on all 10 silver bars. The detailed measurement results can be found in Table 3 . The values fluctuate within the error limits specified by the device manufacturer of $\pm 0.1 \mathrm{MS} / \mathrm{m}$ at room temperature.

Fig. 7 shows wave-like fluctuations in the conductivity of the bars. There are some bars such as B3 and B9; these bars have a higher conductivity than the rest. This is perhaps due to the silver content of the bars.

The average conductivity of the obverse is $22.05 \pm 1.70$ and the reverse $16.07 \pm 2.47 \mathrm{MS} / \mathrm{m}$. As can be seen from the results, avers has a higher conductivity than the reverse. That means the obverse has a higher fineness than the reverse. This is proof that the bars slowly solidified from the obverse so that segregation has occurred (Fig. 8).

There is a $5.98 \mathrm{MS} / \mathrm{m}$ average conductivity difference between the front and back. This discrepancy might be

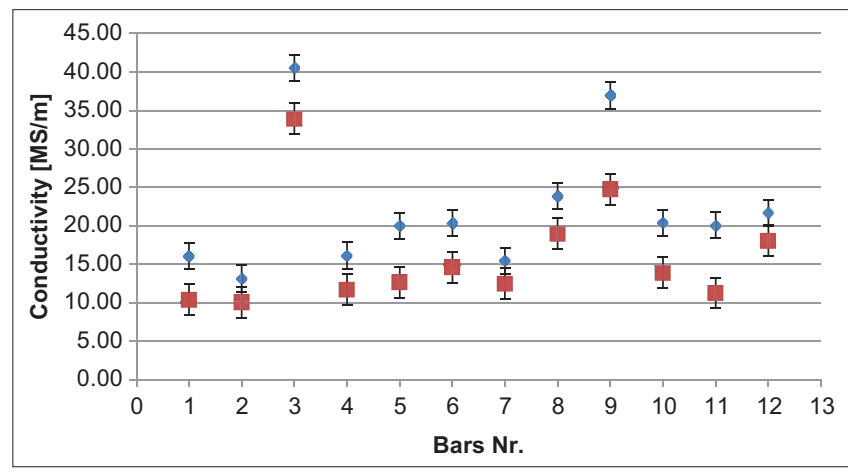

Fig. 7. Average conductivities on the obverse and lapel. $>$ Blue conductivity of the obverse (MS/m), $\square$ Red Conductivity of the revers $(M S / m)$.

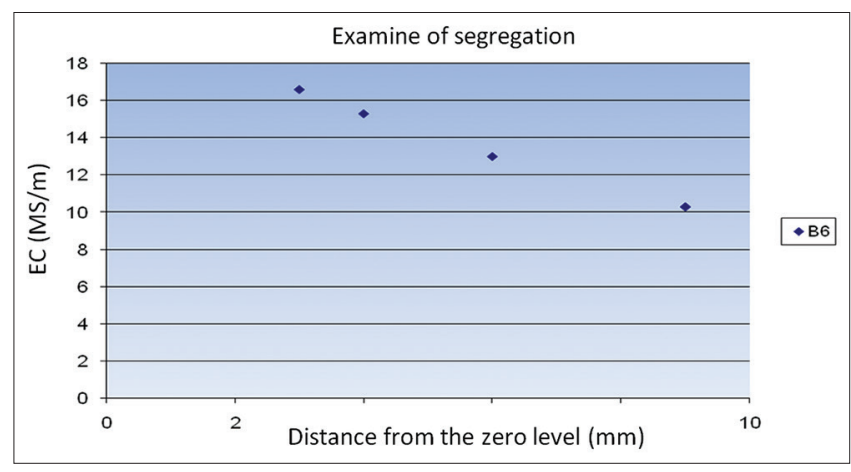

Fig. 8. Conductivity curve on the bar 6 . 
produced by a variety of factors, including device limitations, corrosion layers, and fineness changes from front to back, such as more silver on the front than the opposite.

The segregation of the bars was investigated. The technique of separating distinct items in an observation area is referred to as segregation. A zero level was established on the bars for this reason. The transition from obverse to reverse was specified at the zero levels. Segregation on the bars can be noticed if the conductivity diminishes proportionately to the distance from the zero levels.

All bars were subjected to the segregation test. It was not feasible to prove that segregation had occurred in the case of certain bears. There is no decreasing conductivity curve as one moves away from the zero height, as there is for bars B1, B8, and B9. This might result in no solidification on these bars from the Avers to the Revers.

Influence of the stamps on the conductivity (EC);

The influence of the stamps on the conductivity was investigated. According to the theory, the stamping should result in lower conductivity. The results are shown in Table 4.

According to theory, stamping should result in lower EC, but this difference does not seem to be significant, that is, on the Revers, segregation is probably the main cause of the various EC.

\subsection{Measurements by the SEM}

The goal is to learn about the equipment and how to utilize SEM, as well as to learn about the surface characteristics of the bars. A SEM was used to record the following bars at various positions on the bars, and quantitative determinations were achieved using energy-dispersed X-ray fluorescence analysis (EDX) through intensity measurements element-specific wavelength (Fig. 9).
For image B3-05, EDX was made on a wise matrix, on points and dark points (Fig. 10).

The results are given in the table below.

In Table 5, it is clear that the dark points are predominantly made of carbon. The $\mathrm{Cl}$ content determined whether the salts have formed on the surface of the bar, but it cannot be clearly stated that the salts have formed because the $\mathrm{Cl}$ content is too small.

With the SEM-EDX, light elements such as carbon and oxygen were detected compared to the $\mu$-XRF

Image B5-01 was taken to determine whether the drawings can be recognized as writing. The drawings suggest the scriptures to some extent (Fig. 11).

An attempt was made in image B5-08 to clarify whether or not it is a "M" letter. However, it is not as obvious (Fig. 12).

\subsection{XRF Analysis}

The measurements with $\mu$-XRF analysis aimed to determine the fineness and the components of the bars B1, B2, B3, B4, B6, B8, B9, B10, ВT1, ВT3, ВT6.

The "Eagle $\mu$-Probe II" device from EDAX was used for the measurement. The device has an X-ray tube with a beryllium window, rhodium target, an acceleration voltage of 10 to 40 $\mathrm{keV}$, a cathode current of 40 to $1000 \mu \mathrm{A}$ and a Si (Li) detector was used as a detector.

For each bar, 20 points were placed on the obverse and 20 points on the reverse, resulting in a generally circular form. Table 6 shows the corrected findings after adding the standards to the basic parameter correction. Silver

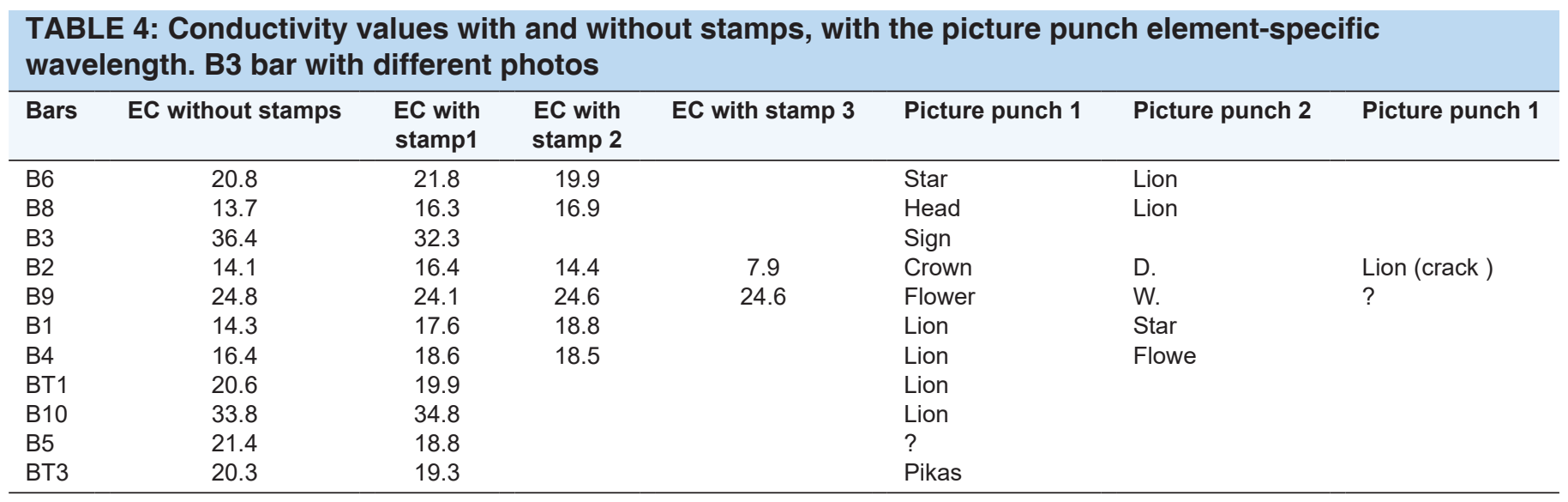


TABLE 5: The chemical composition of B3-05

\begin{tabular}{lccc}
\hline Elements & Wise Matrix & Point & $\begin{array}{c}\text { Dark } \\
\text { structure }\end{array}$ \\
\hline $\mathrm{C} \%$ & 6,5 & 44 & 38 \\
$\mathrm{O} \%$ & 1.2 & 8 & 8 \\
$\mathrm{Cl} \%$ & 0.6 & 0.1 & 2 \\
$\mathrm{Ag} \%$ & 88.6 & 4 & 45 \\
$\mathrm{Cu} \%$ & 0.7 & 36 & 1 \\
$\mathrm{~Pb} \%$ & 2.3 & 6 & 5 \\
\hline
\end{tabular}

was found as the major component in all twelve bars, with copper and lead as minor components. The bars contain a silver composition of 6.494 .07 percent by weight copper and 6.383 .28 percent by weight lead, with an average of 87.635 .86 percent by weight. There are extremely high standard variations with an average copper and lead concentration. This demonstrates how the copper and lead contents of each ingot vary greatly. The silver content has

\section{TABLE 6: Measuring the weight percentage of silver bar samples by $\mu$-XRF of both sides}

\begin{tabular}{|c|c|c|c|c|c|c|}
\hline Sample ID & Side & Obverse & AgK & AgL & $\mathrm{Cu}$ & $\mathrm{Pb}$ \\
\hline \multirow[t]{3}{*}{ B1 } & Obv. & Average & 85.944 & 87.013 & 7.779 & 6.278 \\
\hline & & STD & 3.179 & 3.057 & 2.451 & 1.981 \\
\hline & Rev. & Average & 77.239 & 78.268 & 10.103 & 12.659 \\
\hline \multirow[t]{3}{*}{ B2 } & Obv. & Average & 81.678 & 89.595 & 13.085 & 5.237 \\
\hline & & STD & 6.739 & 2.613 & 4.287 & 4.218 \\
\hline & Rev. & Average & 89.922 & 88.340 & 4.295 & 5.737 \\
\hline \multirow{3}{*}{ B3 } & & STD & 4.201 & 2.342 & 2.509 & 2.482 \\
\hline & Rev. & Average & 96.593 & 96.264 & 2.014 & 1.395 \\
\hline & & STD & 1.829 & 2.042 & 0.639 & 1.742 \\
\hline \multirow[t]{4}{*}{ B4 } & Obv. & Average & 82.717 & 89.601 & 8.261 & 9.024 \\
\hline & & STD & 4.854 & 3.715 & 1.481 & 5.440 \\
\hline & Rev. & Average & 85.966 & 85.995 & 4.746 & 9.289 \\
\hline & & STD & 4.507 & 3.457 & 1.430 & 4.324 \\
\hline \multirow[t]{4}{*}{ B6 } & Obv. & Average & 81.312 & 88.461 & 9.256 & 9.331 \\
\hline & & STD & 4.501 & 3.226 & 1.987 & 3.286 \\
\hline & Rev. & Average & 91.031 & 92.098 & 5.110 & 3.853 \\
\hline & & STD & 4.520 & 3.465 & 1.537 & 3.085 \\
\hline \multirow[t]{4}{*}{ B8 } & Obv. & Average & 87.359 & 90.729 & 6.040 & 6.601 \\
\hline & & STD & 6.388 & 3.862 & 3.734 & 4.317 \\
\hline & Rev. & Average & 91.333 & 90.635 & 2.875 & 5.793 \\
\hline & & STD & 2.747 & 4.778 & 0.936 & 2.864 \\
\hline \multirow[t]{4}{*}{ B9 } & Obv. & Average & 94.835 & 95.275 & 1.867 & 3.297 \\
\hline & & STD & 1.210 & 0.765 & 0.352 & 1.163 \\
\hline & Rev. & Average & 93.847 & 93.689 & 2.809 & 3.316 \\
\hline & & STD & 3.089 & 3.438 & 0.379 & 3.056 \\
\hline \multirow{3}{*}{ ВT3 } & & STD & 8.160 & 5.540 & 7.690 & 3.590 \\
\hline & Rev. & Average & 69.948 & 83.247 & 15.648 & 13.300 \\
\hline & & STD & 4.708 & 3.152 & 3.581 & 3.668 \\
\hline \multirow[t]{4}{*}{ ВT6 } & Obv. & Average & 89.701 & 89.433 & 4.892 & 5.408 \\
\hline & & STD & 4.233 & 4.187 & 2.112 & 2.533 \\
\hline & Rev. & Average & 75.963 & 88.397 & 13.644 & 10.393 \\
\hline & & STD & 10.026 & 3.254 & 4.820 & 7.771 \\
\hline
\end{tabular}


the highest B9 bar, with an approximate value of the copper and lead content have the maximum BT3 bar, with around 95.14 percent and 12 percent, respectively.

The iron and gold composition of the bar could be determined. That was not accomplished in our effort. Table 7 shows the ratio of the intensities of the generated $\mathrm{Ag}-\mathrm{K}$ and $\mathrm{Ag}-\mathrm{L}$ signals to determine the thickness of the corrosion layer.

According to the AgK/AgL ratios, the obverse of all Roman bars has a slightly thicker corrosion layer than the reverse. This might be owing to a site-specific storage facility in the earth or other unique features.

\section{CONCLUSION}

The conductivity of the bars is shown by wave-like variations. The conductivity of the B3 and B9 is greater than that of the others. This is because the bars contain silver.

The average conductivity of the obverse is $22.05 \pm 1.70$ and the reverse $16.07 \pm 2.47 \mathrm{MS} / \mathrm{m}$. Obvers has a higher conductivity than the reverse. That means obverse has a higher fineness than revers. This is proof that the bars have slowly solidified from the obverse so that segregation has occurred.

TABLE 7: AgK/AgL ratio of difference silver bars

\begin{tabular}{lcccccc}
\hline & \multicolumn{7}{c}{ *AgK/AgL Ratio } \\
\cline { 2 - 7 } & B1 & B2 & B3 & B4 & B5 & B6 \\
\hline Obvers & 0.088 & 0.081 & 0.075 & 0.092 & 0.098 & 0.091 \\
Revers & 0.098 & 0.090 & 0.088 & 0.097 & 0.099 & 0.094 \\
\hline & B8 & B9 & B10 & BT1 & BT3 & BT6 \\
\hline Obvers & 0.076 & 0.074 & 0.085 & 0.096 & 0.077 & 0.071 \\
Reverse & 0.094 & 0.079 & 0.099 & 0.010 & 0.084 & 0.085 \\
\hline
\end{tabular}

The peak intensities of AgK and AgL line are measured as cps/eV[18]

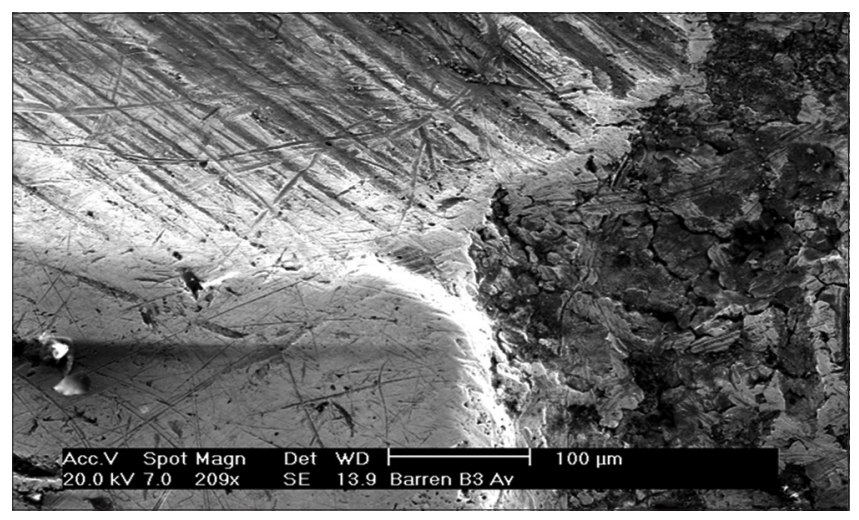

Fig. 9. Image B3-01: Photo at the point where is the castingdemolition transition.
All bars were subjected to the segregation test. In the instance of certain bars, it was not always feasible to state unequivocally that segregation had happened. There is no diminishing conductivity curve as one moves away from the zero height, as there is for bars B1, B8, and B9. As a result, there may be no solidification on these bars from obvers to reveres.

A SEM was used to record the following bars at various positions on the bars, and quantitative determinations were achieved using EDX through intensity measurements of the element-specific wavelength.

The measurements with $\mu$-XRF analysis aimed to determine the fineness and the components of the bars B1, B2, B3, B4, B6, B8, B9, B10, BT1, BT3, BT6.

For each bar, 20 points were placed on the obverse and 20 points on the reveres, resulting in a generally circular form. In all twelve bars, silver was identified as the main component and copper and lead as the minor component. With an average of $87.63 \pm 5.86 \%$ by weight, the bars have a silver content of $6.49 \pm 4.07 \%$ by weight copper and $6.38 \pm 3.28 \%$ by weight lead. With an average copper and lead content, there are very large standard deviations.

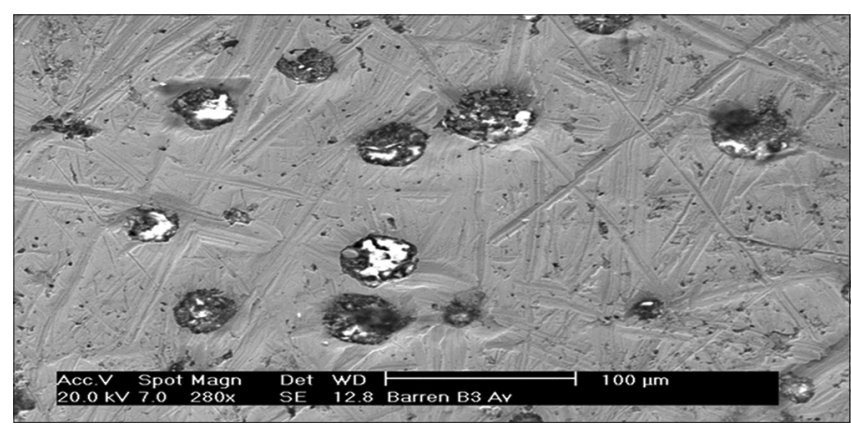

Fig. 10. Image B3-05: The obverse image of round inclusions [18].

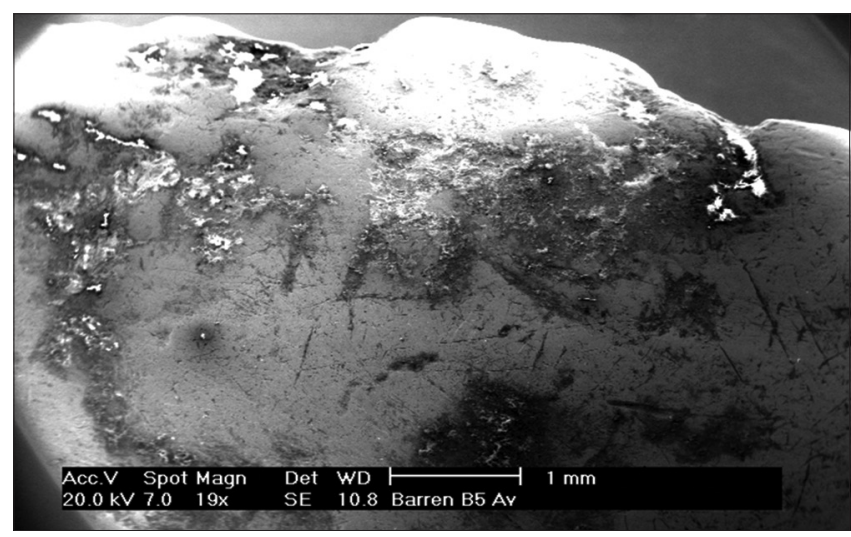

Fig. 11. Image B5-01: Photo of bar B5. 


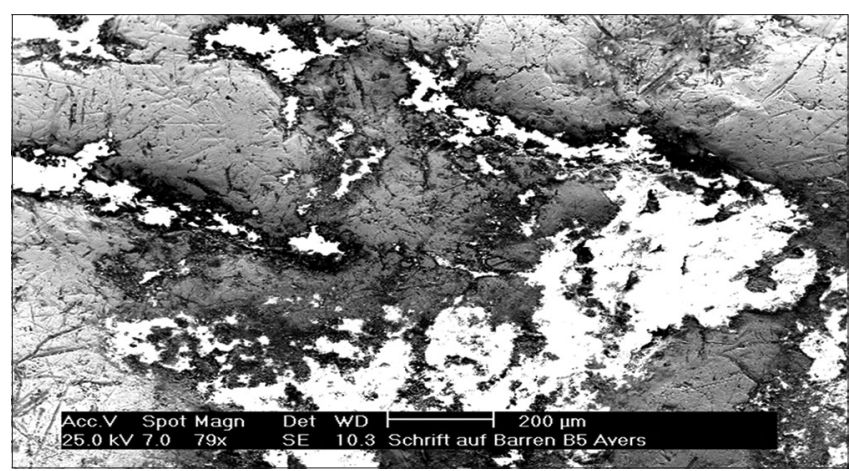

Fig. 12. Image B5-08: Writing on obverse B5 bar.

This shows that the copper and lead contents of each ingot vary widely. The silver content has the highest B9 bar with approx. 95\%, the copper and lead content have the highest BT3 bar with approx. $14 \%$ and $12 \%$. The iron and gold composition of the bar may be analyzed. That was not done in our work. According to the $\mathrm{AgK} / \mathrm{AgL}$ ratios, the reverse of all silver bars (B1, B2, B3, B4, B5, and B6) has a somewhat thicker corrosion layer than the face. This might be owing to a location-specific storage facility in the earth or other particular properties.

\section{REFERENCES}

[1] H. J. Eggers. "Zur Absoluten Chronologie der römischen Kaiserzeit im Freien Germanien". In: Aufstieg u. Niedergang röm. Welt II, pp. 3-6, 1976.

[2] M. Pfefferkorn. "Seit 4000 Jahren Zahlungsmittel, Vorstufen des Münzgeldes-Vom Bronzebarren Zum Goldenen Oban, Moneytrend", vol. 9, pp. 118-122, 2003.

[3] R. Lehmann. "Barren versus Münze, Teil I: Barrengeld Damals Und Heute Und Die Besondere Bedeutung im Mittelalter, Moneytrend", vol. 10, pp. 134-139, $2010 \mathrm{~b}$.

[4] T. Lautz. "Barren als Zahlungsmittel. Von der Bronzezeit Bis Ins 20.
Jahrhundert, Das Fenster in der Kreissparkasse Köln, Thema 163, Köln", 2003.

[5] A. Anikin. "Gold, Verlag Die Wirtschaft, Berlin", pp. 77-80, 1982.

[6] K. Reiter. "Die Metalle im Alten Orient unter besonderer Berücksichtigung Altbabylonischer Quellen, Ugarit-Verlag, Münster", pp. 43, 47, 83-103, 113, 289, 299-305, 401, 405-415, 425, 435-437, 452, 455, 1997.

[7] K. Volke. "Zu den Anfängen der Analytischen Chemie: Wider Fälscher und Betrüger, Chemie in unserer Zeit". $4^{\text {th }}$ ed. WILEYVCH Verlag, Weinheim, pp. 268-275, 2004.

[8] R. Wiegels. "Silberbarren der Römischen Kaiserzeit, Katalog und Versuch Einer Deutung, Freiberger Beiträge zur Archäologie und Geschichte des Ersten Jahrtausends, Rahden/Westf', 2004.

[9] L. Biosas. "Griechische Münzen, Faszination und Geschichte, Numismatischer Verlag Fritz Rudolf Künker, Osnabrück", pp. 493-504, 2005.

[10] F. Schrötter. "Wörterbuch der Münzkunde, de Gruyter Verlag, Berlin", 1930.

[11] B. Kluge. "Die Monetarisierung Europas in Staufischer Zeit, Numismatisches Nachrichtenblatt (NNB), 09/2010, 14150", pp. 325-331, 2010.

[12] R. Lehmann and C. Vogt, C. "Wer Den Pfennig nicht Ehrt lst Die Mark Nicht Wert?" 2010a.

[13] “W. Szaivert-R. Wolters, Löhne, Preise", 2005. Available from: https://www.w.pd.file:///e:/research2021/xrf\&sem/referances/“no title. [Last accessed on 2021 Nov 12].

[14] A. Loehr. "Probleme der Silberbarren, Numismatische Zeitschrift, Wien", vol. 24, pp. 101-109, 1931.

[15] H. Ehrhardt. "Röntgenfluoreszenzanalyse-Anwendung in Betriebslaboratorien". $2^{\text {nd }}$ ed. Springer-Verlag, Berlin, 1989.

[16] C. Vogt. "Skript zur Vorlesung, Grundlagen der Analytik I, Röntgenspektroskopie, Universität Hannover", 2006.

[17] A.Feldhoff,2007.Availablefrom:https://www.notitlefile:///f:/localdisk/ analytikvorlesungungen.vogt/fortgeschrittenematerialanalytik/ materialanalytik-i-2007-feldhoff.pdf. [Last accessed on 2021 Oct $11]$.

[18] S. M. M. Hrnjić, G. A. Hagen-Peter,T. Birch, G. H. Barfod, S. Sindbæk and C. E. Lesher. "No Title Non-Destructive Identification of Surface Enrichment and Trace Element Fractionation 4 in Ancient Silver Coins", 2020. 